\title{
İki Ucu Ankastre U Çerçeve Yapının Modal Analizi
}

\author{
Mesut HÜSEYINOĞLU1 $\mathscr{\&}$, Tayfun ABUT ${ }^{2}$ \\ ${ }^{1}$ Makine Mühendisliği, Mühendislik Fakültesi, Dicle Üniversitesi, Diyarbakır, Türkiye \\ ${ }^{2}$ Makine Mühendisliği, Mühendislik-Mimarlık Fakültesi, Muş Alparslan Üniversitesi, Muş, Türkiye \\ $\bowtie$ : mesuth@dicle.edu.tr (iD) 0000-0002-6130-6658, Tayfun ABUT (iD) 0000-0003-4646-3345
}

Geliş (Received): 24.10.2019Ｄüzeltme (Revision): 03.12.2019～Kabul (Accepted): 05.12.2019

\section{ÖZ}

Endüstride kullanılan birçok makine elemanının dinamik davranışlarının belirlenmesi, yapının güvenli bir şekilde çalışması ve makinenin performansı açısından oldukça önemli bir konudur. Modal analiz tekniği yapıların dinamik özelliklerinin belirlenmesi amacıyla yaygın bir şekilde kullanılmaktadır. Bu çalışmada iki ucu ankastre bir U çerçeve yapının teorik ve deneysel modal analizleri gerçekleştirilmiştir. Teorik modal analiz ANSYS programı kullanılarak yapılmıștır. Deneysel modal analiz ise OROS Or36 titreşim analizörü ve OROS modal analiz yazılımı ile gerçekleştirilmiş̧tir. Deneysel ve teorik çalışmalardan elde edilen sonuçlar karşılaştırılmış ve ANSYS’te oluşturulan modelin deneysel modeli başarılı bir şekilde temsil ettiği görülmüştür.

Anahtar Kelimeler: Modal Analiz, Çerçeve Yapılar, Sonlu Elemanlar, Titreşim Ölçümü

\section{Modal Analysis of a Clamped-Clamped U Frame Structure}

\begin{abstract}
Determining of dynamic behaviours of the many machine elements used in the industry is an important issue in terms of the safe operation of the structure and the performance of the machine. Modal analysis method is widely used to determine the dynamic properties of the structures. In this study, theoretical and experimental modal analyses of a clamped-clamped $U$ frame. Theoretical modal analysis is performed using ANSYS programme. Experimental modal analysis is performed with OROS Or36 vibration analyser and OROS modal analysis software. The results obtained from experimental and theoretical studies were compared and it was found that the model created in ANSYS successfully represented the experimental model.
\end{abstract}

Keywords: Modal Analysis, Frame Structures, Finite Elements, Vibration Measurement

\section{GíRiş}

Titreşim hareketi yapının denge konumu etrafında tekrarlanan hareketi olarak tanımlanabilir. Dinamik yükler etkisi altında çalışan sistemlerde de tekrarlı bir hareket olan titreşim hareketi meydana gelmektedir. Mekanik titreşimler mühendislik yapılarının çoğunda önemli problemlere neden olabilmektedir. Uzun süreli titreşimler makine elemanının yorulmasına neden olabileceği gibi yüksek genlikteki titreşimler de hasar ve kırılmalara neden olabilmektedir. Bu nedenle endüstride kullanılan birçok yapı elemanının dinamik yükler etkisi altında nasıl bir davranış gösterdiği, sistemin güvenli bir şekilde çalışması ve performansı açısından oldukça önemlidir. $\mathrm{Bu}$ amaçla incelenen yapının doğal frekansları, yapısal sönümü ve titreşim biçimleri elde edilerek gerekli dinamik analizler yapılmalıdır. Yapılan dinamik analizler sonucunda istenmeyen titreşimleri azaltmak için titreşim kaynağını durdurmak veya sistem üzerinde yapısal değişiklikler yapmak gereklidir. Bunların sağlanamadığı durumlarda ise titreşim kaynağının sistem üzerine olan etkisini azaltmak için uygun bir titreşim yalıtım sistemi tasarlanabilir. Titreşim yalıtımını gerçekleştirebilmek için titreşim kaynağı ve yap1 arasına sönüm kabiliyeti yüksek malzemeler yerleştirilir veya uygun dinamik titreşim sönümleyicileri tasarlanır.

Sonlu Elemanlar (SE) yöntemi yapıların dinamik özelliklerinin belirlenmesinde oldukça etkili bir şekilde kullanılmaktadır. SE metodu; karmaşık olan problemlerin daha basit alt problemlere ayrilarak her birinin kendi içinde çözülmesiyle genel çözümün bulunduğu bir çözüm şeklidir. SE metodu oldukça sistematik ve modülerdir. Bundan dolayı SE metodu, bir bilgisayar programı hazırlanarak geniş alandaki pratik titreşim problemlerinin çözümü için kolaylıkla bir bilgisayara uygulanabilmektedir. Günümüzde çok sayıda ticari SE yazılımları mevcuttur ve bu yazlımlar normal bilgisayarlardan süper bilgisayarlara kadar hemen hemen her tip bilgisayarda çalıştırılabilmektedir. SE yöntemi ile bir sistemin analizi iki adımda gerçekleştirilir. Birinci adım, tasarımı gerçekleştirilmiş yapının sonlu sayıda küçük temel parçalara 
bölünmesidir. Bu küçük parçalara sonlu elemanlar ve yapının sonlu elemanlara bölünmesi işlemine ise ayrıklaştırma adı verilmektedir. Her eleman, hareket denkleminin kolay bir şekilde çözülebilmesi veya yaklaşımın kolay uygulanabilmesi için genellikle kolon, kiriş veya plak gibi çok temel şekildedir. Tüm bu elemanların geometrik ve fiziksel özellikleri dikkate alınarak çözüm aşamalarının belirlenmesi ve sistemin tümüyle analizlerinin gerçekleştirilmesi ikinci adımı oluşturmaktadır [1].

Modal analiz tekniği, yapıların dinamik özelliklerin belirlenmesi amacıyla birçok araştırmaya çalışma konusu olmuştur. Chen ve Ding [2], elastik bir küresel kabuk yapının serbest titreşimleri için modal analiz tekniğini kullanmışlardır. $\mathrm{Bu}$ amaçla, yazarlar tarafindan geliştirilen üç boyutlu esneklik çözüm yöntemi kullanılmıştır [3]. Wu ve Heyliger [4], tabakalı piezoelektrik küresel kabukların simetrik ve simetrik olmayan eksenel titreşimleri için iki boyutlu birinci dereceden kaymalı deforme olabilen kabuk teorisi kullanarak modal analiz tekniğini uygulamışlardır. Lee [5], küresel kapakların simetrik ve simetrik olmayan eksenel serbest titreşimlerinin analizinde psödospektral yöntemi kullanmıştır. Krawczuk vd. [6], çatlak ve tek yönlü kompozit kirişin modal analizini yapmışlardır. Enine yorulma çatlağı içeren kompozit kirişin karakteristik matrislerini oluşturmak için bir model sunmuşlardır. Bu model ile çatlak parametreleri (konum ve bağıl derinlik) ve malzeme parametrelerinin (bağıl hacim ve elyaf açısı) ilk dört doğal frekans üzerindeki etkisini araştırmışlardır. Maurinia vd. [7] kademeli piezoelektrik kirişlerin modal analizi için sayısal yöntemler üzerinde çalışmışlardır. Çalışmada, EulerBernoulli kiriş teorisi kullanılarak modellenen kademeli piezoelektrik kirişler, modal analiz için farklı sayısal yöntemleri analiz etmek amacıyla kullanılmıştır. Hee vd. [8], konsol kirişlerinin modal analizini, şekil ve şekil optimizasyonu üzerinden incelemişlerdir. Gao [9], fiziksel sistem parametrelerini dikkate alarak kafes yapıların modal analizini incelemiştir. $\mathrm{Xu}$ ve Zhang [10], bağlantı damperleri olan çelik çerçevelerin modal analizi ve sismik tepkisini araştırmışlardır. Sırasıyla, döner uçlu yay ve sönümleyici olarak cıvatalı bağlantıları ve sönümleyicileri iyileştirmek için SE ve direngenlik yöntemlerinin bir kombinasyonunu kullanarak çerçeve için kütle, direngenlik ve sönüm matrislerini türetmişlerdir. Karmaşık mod analizi kullanılarak, çerçevenin dinamik özellikleri analiz edilmiş ve bağlantı sertliği ile dönme sönümleyicisinin doğal frekans ve modal sönüm oranına etkileri incelenmiştir. Chan [11], esnek biçimde bağlı çelik çerçevelerin daha genel bir titreşim ve kararlılık analizini kapsayan çerçeveli yapıların analizleri için direngenlik matrisi analiz yönteminin genişletilmesine yönelik bir çalışma sunmuştur. Bu çalışmada ise $\mathrm{U}$ çerçeve bir yapının teorik ve deneysel modal analizleri yapılarak sonuçlar karşılaştırmalı bir şekilde sunulmuştur.

\section{MATERYAL ve YÖNTEM}

\section{Teorik Modal Analiz}

Çok serbestlik dereceli (SD'li) bir sistemin zorlanmış titreşim cevabının elde edilmesi, dinamik direngenlik $[Z]$ 'nin tersinin $\left([H]=[Z]^{-1}=\left[-\omega^{2}[M]+[K]\right]^{-1}\right)$ her $\omega$ frekans noktası için hesaplanması ile mümkün olmaktadır. Bu durum oldukça zaman alan zahmetli bir işlemdir. Modal analiz, dinamik analiz işlemlerinde bu olumsuzlukları kayda değer bir biçimde azaltan etkili bir yöntemdir. $\mathrm{Bu}$ yöntem titreşim hareketi yapan bir sistemin dinamik davranışını gösteren matematik modeli oluşturmak için ihtiyaç duyulan modal parametrelerin belirlenmesi işlemidir. Sönümsüz bir sistemin modal parametreleri öz değerler (doğal frekansların karesi) ve öz vektörlerden (mod şekilleri) oluşmaktadır. Eğer yapı üzerinde herhangi bir zorlayıcı kuvvet yoksa $(\{f(t)\}=\{0\})$ yapı doğal titreşim yapmaktadır ve bu durumdaki öz değerler ve öz vektörler yapının doğal veya normal modları olarak adlandırılmaktadır [12].

Sönümsüz yapıların titreşimine ait hareket denkleminin çözümü için $\{x(t)\}=\{X\} e^{i \omega t}$ çözümü dikkate alınacak olursa;

$$
\left(-\omega^{2}[M]+[K]\right)\{X\} e^{i \omega t}=\{F\} e^{i \omega t}
$$

elde edilir. Yapının normal modlarının dikkate alınmasıyla, $\{F\}=\{0\}$ olacağından çözüm aşağıdaki gibi olmaktadır:

$$
\left(-\omega^{2}[M]+[K]\right)\{X\}=\{0\}
$$

Bu denklemde $N$ SD'li bir sistem için $N$ mod sayısı mevcuttur. Eğer mod şekilleri ve doğal frekanslar sırası ile $\{\psi\}_{r}$ ve $\omega_{r}$ ile gösterilecek olursa;

$$
\begin{aligned}
& \left(-\omega_{r}^{2}[M]+[K]\right)\{\psi\}_{r}=\{0\} \\
& r=1,2,3, \ldots \ldots . N
\end{aligned}
$$

eşitliği elde edilir. Ayrıca $r$ modunun öz değeri, $\lambda_{r}=\omega_{r}^{2}$ ile gösterilmektedir. Modal analizde $N$ tane mod dikkate alınarak oluşturulan model "Modal Model" olarak adlandırılmaktadır [7]. Bu durumda öz değerler ve öz vektörler aşağıdaki gibi $N x N$ boyutunda matrisler olarak ifade edilmektedir.

$$
\left[\begin{array}{lll}
\ddots & & \\
& \lambda_{r} & \\
& & \ddots
\end{array}\right]_{N \times N} \quad[\Psi]_{N \times N}
$$


Eşitlik (4) ile verilen öz değerler ve öz vektörlerin çözümünü yapabilmek için bazı sayısal yöntemler mevcuttur. SD'si küçük olan $(N<1000)$ sistemler için, tüm sistem matrisleri belirlenir ve tüm modlar dikkate alınarak çözüm yapılır [13]. Ancak pratik uygulamalarda, SD çok fazladır $(N \gg 1000)$ ve bu durumlarda sadece $N$ modun $m$ kısmını içeren kısmi çözümler yapılır [14].

Öz değer ve öz vektör çözümlerinin hesaplanması oldukça zahmetli bir iş olmasına rağmen modal model iyi bilinen ortagonallik özelliğine sahiptir ve bu durum sistemin analizini büyük ölçüde basitleştirmektedir. Mod şekillerinin ortagonalliği kısaca (5) eşitliğindeki gibi ifade edilebilir.

$$
\begin{aligned}
& {[\Psi]^{T}[M][\Psi]=\left[\begin{array}{llll}
\ddots & & \\
& m_{r} & \\
& & \ddots
\end{array}\right]} \\
& {[\Psi]^{T}[K][\Psi]=\left[\begin{array}{llll}
\ddots & & \\
& k_{r} & \\
& & \ddots
\end{array}\right]}
\end{aligned}
$$

Öz vektör matrisi sistemin kütle, $[M]$ ve direngenlik, $[K]$ matrislerini modal kütle, $m_{r}$ ve modal direngenlik, $k_{r}$ şeklinde diyagonal matrisler haline getirmektedir. $\mathrm{Bu}$ diyagonal modal kütle ve direngenlik matrisleri kullanılarak aşağıdaki gibi öz değerler elde edilebilmektedir.

$$
\left[\begin{array}{lll}
\ddots & & \\
& \lambda_{r} & \\
& & \ddots
\end{array}\right]=\left[\begin{array}{lll}
\ddots & & \\
& m_{r} & \\
& & \ddots
\end{array}\right]^{-1}\left[\begin{array}{lll}
\ddots & & \\
& k_{r} & \\
& & \ddots
\end{array}\right]
$$

Her öz vektör kendi doğal frekansına karşılık gelen bir takım bağıl yer değiştirmelerden oluşmaktadır.

Mod şekilleri, $\{\psi\}_{r}$, modal kütleleri, $m_{r}$ ve direngenlikleri, $k_{r}$ elde etmek için öz vektörler genellikle aşağıdaki gibi kütle ile normalize edilirler.

$$
\begin{aligned}
& \{\phi\}_{r}=\frac{1}{\sqrt{m_{r}}}\{\psi\}_{r} \\
& {[\Phi]=\left[\begin{array}{lll}
\ddots & & \\
& m_{r} & \\
& & \ddots
\end{array}\right]^{1 / 2}[\Psi]}
\end{aligned}
$$

$\mathrm{Bu}$ durumda kütle ile normalize edilmiş öz vektörler kullanılarak aşağıdaki eşitlikler elde edilebilmektedir.

$$
\begin{aligned}
& {[\Phi]^{T}[M][\Phi]=[I]} \\
& {[\Phi]^{T}[K][\Phi]=\left[\begin{array}{lll}
\ddots & & \\
& \lambda_{r} & \\
& & \ddots
\end{array}\right]}
\end{aligned}
$$

Kütle ile normalize edilmiş mod şekilleri yapısal dinamik analizlerinde işlem kolaylığı sağladığı için yaygın bir şekilde kullanılmaktadır.

Fiziksel koordinatlardan, $x\{t\}$, birbirinden tamamen bağımsız modal alandaki yeni koordinatlara, $q\{t\}$, geçiş yapılması durumunda hareket denklemi aşağıdaki gibi olacaktır [15].

$\{\ddot{q}(t)\}+\left[\begin{array}{lll}\ddots & & \\ & \lambda_{r} & \\ & & \ddots\end{array}\right]\{q(t)\}=[\Phi]^{T}\{f(t)\}$

Fiziksel yer değiştirmeler ve modal koordinatlar arasında ise $\{x(t)\}=[\Phi]\{q(t)\}$ ilişkisi mevcuttur [15].

Yapılan bazı ölçümler, bazı modların diğerlerinden daha güçlü olduğunu göstermektedir. Bir ölçümdeki modların yapısı, tahrik kuvvetlerinin konumu ve dağılımına bağlı olarak değişebilmektedir. Bu durumda bir yapı herhangi bir noktasından tahrik edilmesi durumunda ölçümdeki tüm modların görülmesi mümkün olmayacaktır. Bu nedenle fiziksel kuvvet vektörü modal koordinatlara dağıtılarak aşağıdaki gibi modal kuvvet vektörü elde edilebilir [15].

$\left\{f_{q}(t)\right\}=[\Phi]^{T}\{f(t)\}$

Görüldüğü gibi modal koordinatlar birbirinden tamamen bağımsızdır ve her koordinat tek SD'li bir sistem gibi düşünülebilir. Eğer modal kuvvet vektörü, $\left\{f_{\mathrm{q}}(t)\right\}$, bazı koordinatlarda küçük değerlere sahip olursa bu koordinatlara karşılık gelen modlar diğerlerinden daha az tahrik edilmiş demektir. Modal kuvvetin sıfır veya sıfıra çok yakın olması durumunda ise ilgili modlar hiçbir şekilde tahrik edilmemiş olacaktır. Eğer analitik model tahminleri yeterli derecede ölçüm sonuçlarına yakın olursa, modal kuvvet vektörü, ilgili modları tahrik eden kuvvet vektörlerini tanımlamak için kullanılabilir. Lineer bir yapının harmonik bir kuvvet vasıtasıyla tahrik edilmesi halinde (1) eșitliği ile verilen hareket denkleminden dinamik esneklik tipindeki (receptance) FTF matrisi, $[\alpha(\omega)]([H(\omega)])$, aşağıdaki gibi olacaktır.

$\left[-\omega^{2}[M]+[K]\right]^{-1}=[\alpha(\omega)]$ 
Burada, $\quad[\alpha(\omega)] \quad$ matrisinin elemanları, $\alpha_{i j}(\omega)=X_{i}(\omega) / F_{j}(\omega)$ eşitliği ile $j$ koordinatından uygulanan tahrik kuvvetine karşılık $i$ koordinatında meydana gelen yer değiştirme miktarının oranı şeklinde verilmektedir. Dinamik esneklik tipindeki FTF matrisi $[K]$ ve $[M]$ gibi simetriktir ve bu simetri karşılıklılık ilkesine göre $\alpha_{i j}(\omega)=\alpha_{j i}(\omega)$ şeklinde verilmektedir. Frekans noktalarının, $\omega$, sayısına göre dinamik esneklik tipindeki FTF'ler, (11) eşitliğinin doğrudan çözümünden elde edilebilir. Ancak her frekans noktası için tüm sistemin matris tersine ihtiyaç olduğu için bu durum oldukça zahmetli ve zaman alıcı bir işlem olmaktadır. Böyle durumlarda modal özelliklerin kullanılması oldukça avantajlıdır. Bazı cebirsel işlemlerden sonra mod şekilleri ve öz değerler kullanılarak (11) eşitliği aşağıdaki gibi elde edilebilir [12].

$$
[\alpha(\omega)]=[\Phi]\left[\begin{array}{llll}
\ddots & & & \\
& \left(\omega_{r}^{2}-\omega^{2}\right) & \\
& & \ddots & {[\Phi]^{T}}
\end{array}\right]^{-1}
$$

Eşitlik (12)'de diyagonal bir matrisin tersi alındığı için cevap matrisinin hesaplanma süresi oldukça kısalmaktadır. Buradan hareketle dinamik esneklik tipindeki FTF'ler aşağıdaki gibi modların toplam şeklinde hesaplanabilir [15].

$$
\alpha_{i j}(\omega)=\sum_{r=1}^{N} \frac{\phi_{i r} \phi_{j r}}{\omega_{r}^{2}-\omega^{2}}
$$
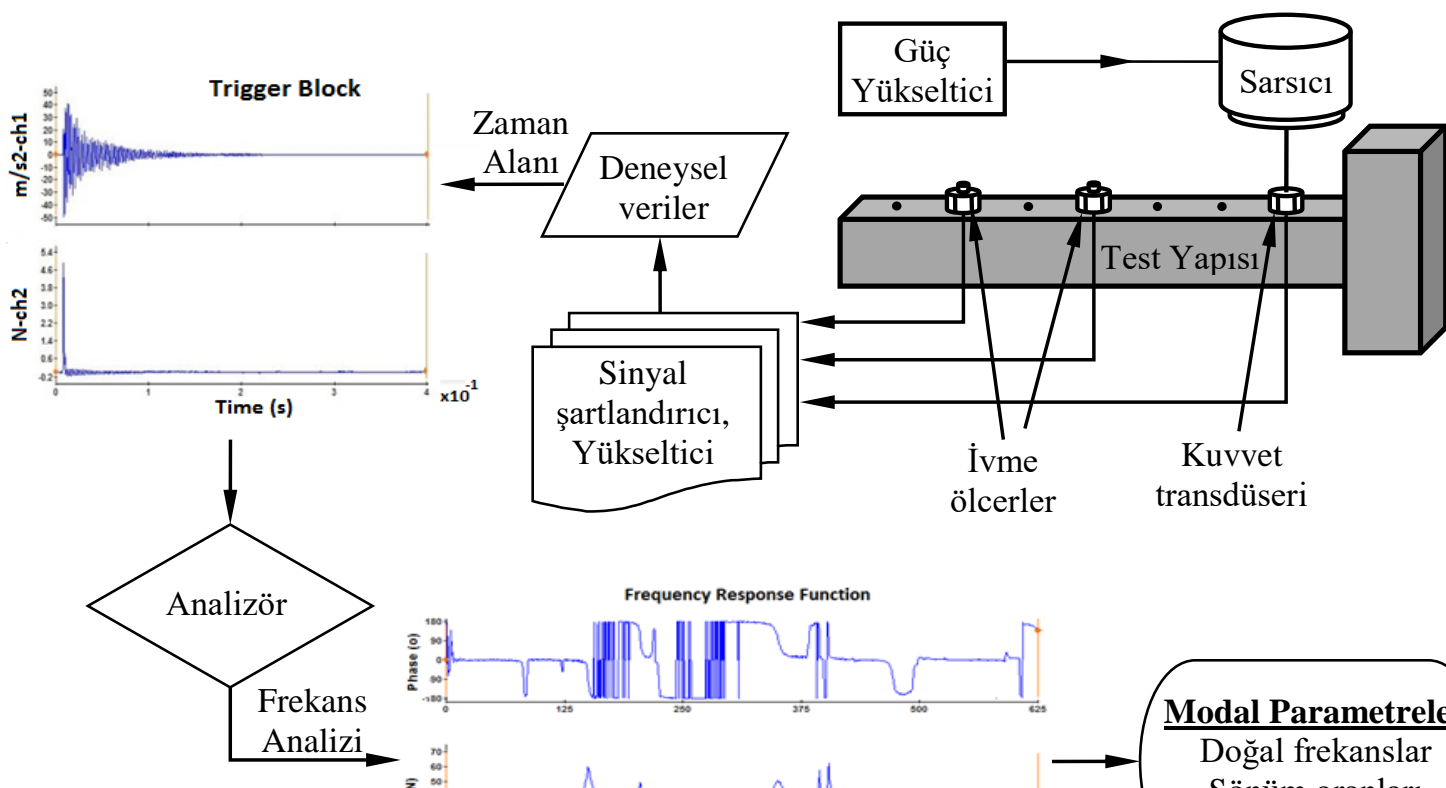

Burada $N$ mod sayısına göre $i$ ve $j$, sirasiyla $r$ modunun öz vektörlerindeki cevap ve tahrik koordinatlarını göstermektedir [15].

Literatürde, büyük yapıların modal analizinde incelenen mod sayısının az sayıda modla sınırlandırılması ve bu sayının, $n$, toplam mod sayısından, $N$, çok küçük $(\mathrm{n}<<\mathrm{N})$ olması gerektiği vurgulanmıştır [15]. Hesaplanan mod sayısı, $n$, genellikle yapılan analizin amacına bağlı olarak belirlenir ve tasarım için önemli olan sadece ilk 3 veya 4 modun sayısı kadar olmaktadır. Ancak bazı durumlarda ise bu sayı ilgilenilen frekans aralığındaki belli modların dikkate alınmasıyla belirlenmektedir.

\section{Deneysel Modal Analiz}

Mühendislik yapılarının tasarımında oluşturulan matematiksel modellerde yapılan yaklaşımların bir sonucu olarak bu modellerden elde edilen sonuçların deneysel olarak doğrulanması tasarım sürecinde önemli bir rol oynamaktadır.

Temel olarak iki çeşit titreşim ölçümü mevcuttur. Bunlardan ilki bir yapının çalışma ortamında sadece titreşim cevabının ölçülmesidir. İkincisi ise yapıya uygulanan bir girişe karşılık yapının verdiği cevabın birlikte ölçülmesidir [12]. Özellikle, yap1 üzerine uygulanan girişe karşılık cevabın ölçülmesi yapının ölçülen frekans tepki fonksiyonlarının (FTF'lerinin) belirlenmesi açısından oldukça önemlidir. $\mathrm{Bu}$ işlem sayesinde test yapısının doğal frekansları ve mod şekilleri belirlenebildiği gibi yapının matematik modelinin doğrulanması işlemi de gerçekleştirilebilmektedir.

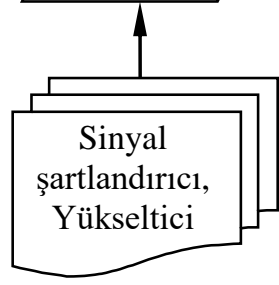

ölcerler

Şekil 1. Deneysel modal analiz ölçüm düzeneği

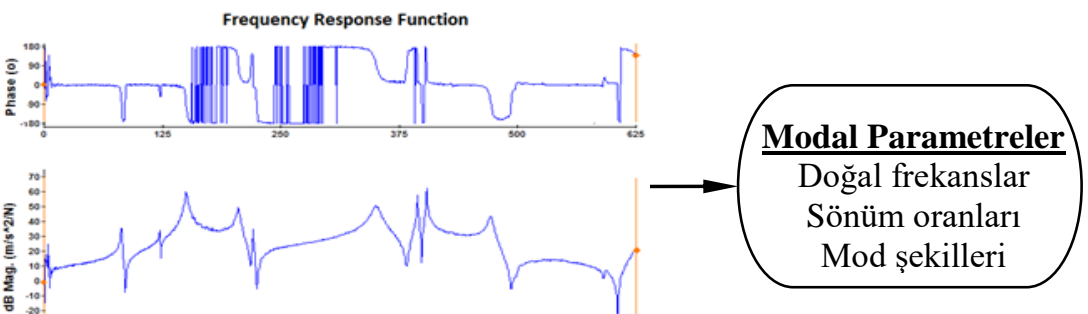


Deneysel modal analizde yapılan deneylerin amacına bağlı olarak, modal analiz veya modal tanımlama işlemi incelenen yapının modal özelliklerinin bulunmasıyla gerçekleştirilmektedir. Burada yapı üzerinde belirli noktalardan tahrik kuvveti uygulanır ve yapının bu etkiye verdiği cevap ölçülerek aradaki transfer fonksiyonları uygun bir titreşim analizörü kullanılarak elde edilmeye çalışılır (Şekil 1). Elde edilen ölçümlerden modal parametrelerin ayıklanması için oluşturulan algoritmalar oldukça zaman alan yoğun uğraşlar sonucunda geliştirilmiştir. Modal parametrelerin elde edilme yöntemleri ve bazı pratik uygulamaları Ewins [12] tarafindan detaylı olarak incelenmiştir.

$\mathrm{Bu}$ çalışmada hem cevap hem de tahrik kuvvetinin eş zamanlı ölçüldüğü ve buna göre yapının dinamik özelliklerinin belirlendiği ölçüm tekniği kullanılmıştır. Titreşim testi konusunda bu yöntemle ilgili farklı yaklaşımlar ifade edilmiştir [12]. Bunlardan biri yapının tek noktadan tahrik edilmesine dayalı ölçüm metodudur. Diğeri ise yapının eş zamanlı olarak birkaç noktasından tahrik edilmesine dayalı ölçüm tekniğidir.

Deneysel modal analizde iki temel tahrik tipi mevcuttur. Bunlar, test aşamasındaki bir yapının darbe çekici veya üzerine bağlanan bir sarsıcı yardımıyla tahrik edilmesi şeklindedir. Test yapısına uygulanan tahrik kuvvetine karşılık yapının verdiği cevap ise ivme, hız veya deplasman transdüserleri gibi elemanlar yardımıyla ölçülmektedir. İvmeölçerler, geniş frekans ve dinamik aralığa sahip ve nispeten ufak yapıda olması sebebiyle en genel amaçlı transdüserlerdir. Hız trandüseri, çoğunlukla orta frekans bölgesini içeren izleme sistemlerinde kullanılmaktadır. Deplasman trandüseri ise özellikle düşük frekanslı deplasman ölçümünün gerektiği eksen kaçıklığı gibi ölçümlerde faydalı olmaktadır. $\mathrm{Bu}$ transdüserlerde ölçüm tek eksende alındığı gibi iki veya üç eksende ölçüm yapabilen tipleri de mevcuttur.

FTF, titreşim testlerinden elde edilen ve çok geniş bir uygulama alanı olan önemli bir fonksiyondur. $\mathrm{Bu}$ fonksiyon, uygulanan bir kuvvete karşı lineer bir yapının gösterdiği tepkiyi ifade eder. Diğer bir ifadeyle yapıya uygulanan kuvvet ile yapının gösterdiği tepki arasındaki lineer ilişkiyi verir (Şekil 2).

Lineer yap1 üzerindeki $q$ konumundan genliği $F$ ve frekansı $\omega$ olan sinüsoidal bir kuvvet uygulandığı zaman yapı bu kuvvete bir tepki gösterecek ve kararlı duruma geçtikten sonra ayn1 frekansta titreşecektir. Yap1 üzerindeki herhangi bir $p$ noktasının bu frekanstaki yer değiştirmesi de (hız veya ivme de olabilir) $X$ olsun. Bu frekans için FTF'nin genliği,

$\left|H_{p q}(\omega)\right|=\frac{\left|X_{p}\right|}{\left|F_{q}\right|}$

ile ifade edilir. FTF'nin fazı ise yer değiştirme ve kuvvet arasındaki açı ile ifade edilmektedir.

$\angle H_{p q}(\omega)=\angle \alpha_{p q}(\omega)=\angle X_{p}-\angle F_{q}=\theta_{\alpha}$

FTF, frekansın bir fonksiyondur. Bu nedenle uygulanan kuvvetin frekansı değiştikçe FTF'nin genliği ve fazı da değişir. Bir FTF, yapıya farklı frekanslarda sinüsoidal kuvvetler uygulanıp her frekansta kuvvet ve tepkilerin genlik ve fazları ölçülerek elde edilebilir.

Yapı üzerindeki kuvvet ve tepki konumları ölçülen FTF'nin türünü belirlemektedir. Bu bağlamda bir FTF yapı üzerinde aynı konum ve doğrultuda ölçülen kuvvet ve tepkiden hesaplanmış ise 'noktasal FTF' (point FRF) olarak adlandırılmaktadır (Şekil 3-a). Kuvvet ve tepki doğrultularının aynı ancak konumlarının birbirinden farklı olması durumu 'transfer FTF' olarak adlandırılır (Şekil 3-b). Bunlara alternatif olarak ölçümler farklı doğrultu ve yönlerde de yapılabilir. Böyle hesaplanan FTF'lere 'çapraz FTF' (cross FRF) denilmektedir (Şekil 3-c).

FTF ölçümlerinde tepki olarak yer değiştirme dikkate alındığı gibi hız ve ivme büyüklükleri de kullanilabilmektedir.

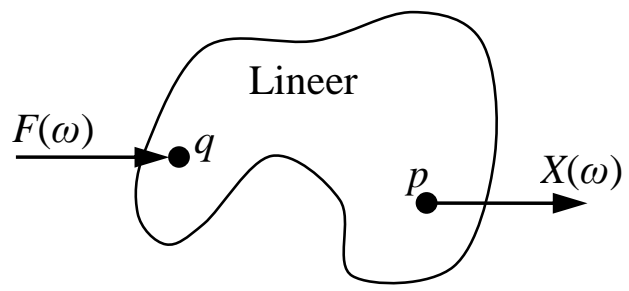

Şekil 2. Lineer bir yapının uygulanan kuvvete karşı gösterdiği tepki

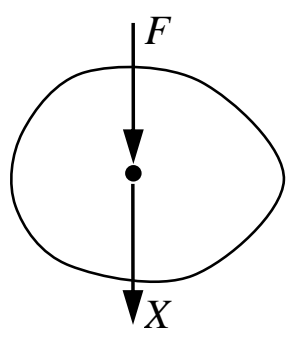

a) Noktasal FTF

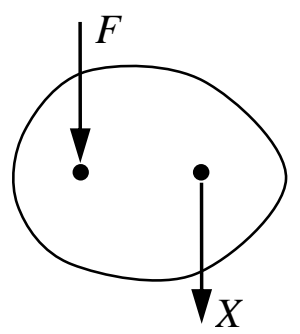

b) Transfer FTF

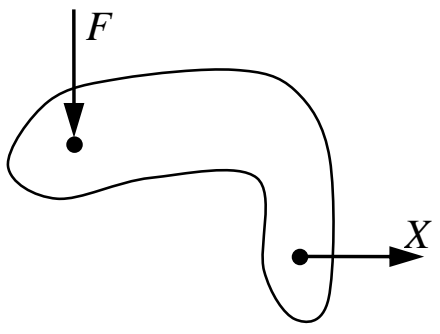

c) Çapraz FTF

Şekil 3. Kuvvet ve tepki konumlarına göre FTF'ler 


\section{TARTIŞMA}

\section{Sayısal Model}

Bu çalışmada dikkate alınan U çerçeve yapının ölçüleri ve mesnet durumları Şekil 4 'te verilmiştir.

Ölçüleri Şekil 4'te verilen U çerçevenin SE modeli BEAM188 (6 SD'li 3 boyutlu elastik eleman) eleman tipi kullanılarak ANSYS'de oluşturulmuştur. Oluşturulan modelin modal analizi ilk 9 mod dikkate alınarak $0-500 \mathrm{~Hz}$ frekans aralığında yapılmıştır. Modal analiz için 'PCG Lanczos' algoritması kullanılmış ve analiz sonucunda elde edilen mod şekilleri ve doğal freknslar sırası ile Şekil 5 ve Tablo 1'de verilmiştir. Tablo 1'den görüleceği üzere $\mathrm{U}$ çerçevenin $\mathrm{SE}$ modeline ait doğal frekanslar $8.81 \mathrm{~Hz}$ ile $292.71 \mathrm{~Hz}$ arasında değişmektedir.

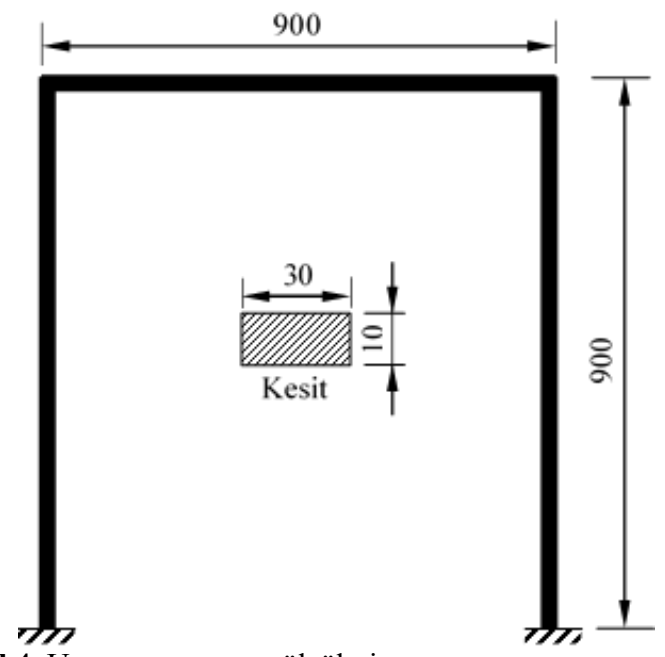

Şekil 4. U çerçeve yapının ölçüleri

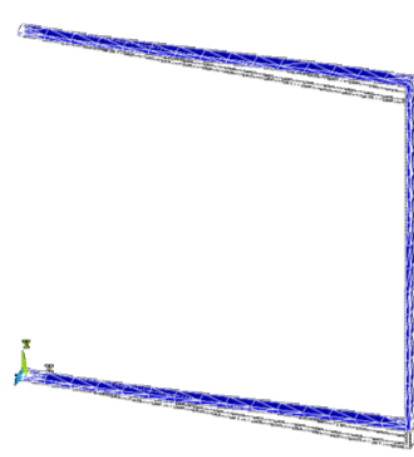

1. $\bmod$

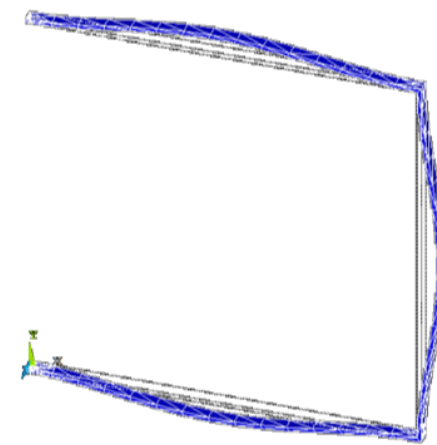

4. $\bmod$

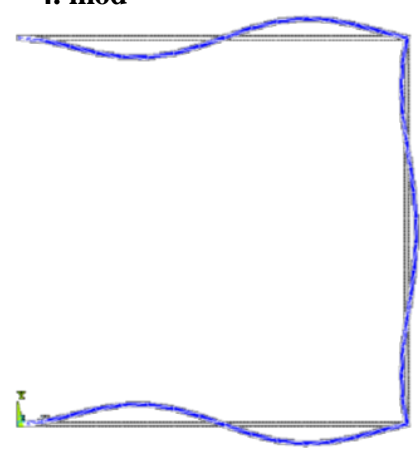

7. $\bmod$

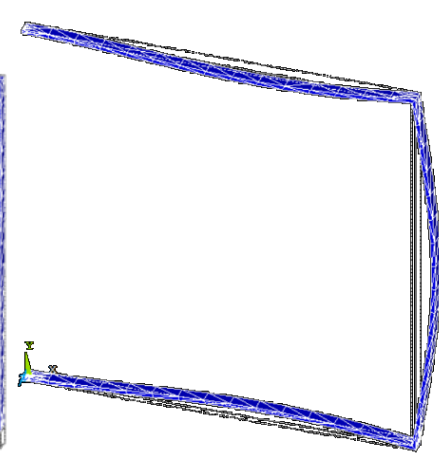

2. $\bmod$

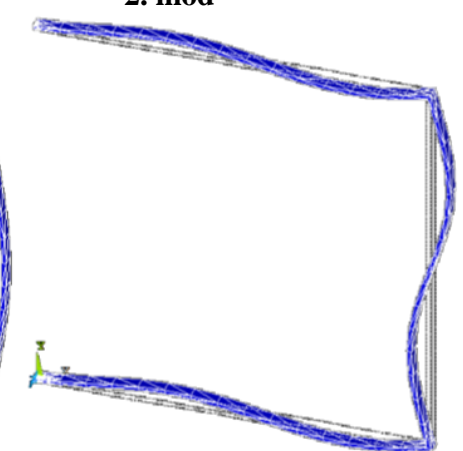

5. $\bmod$

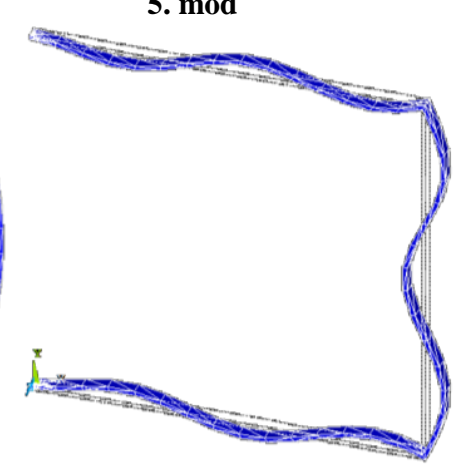

8. $\bmod$

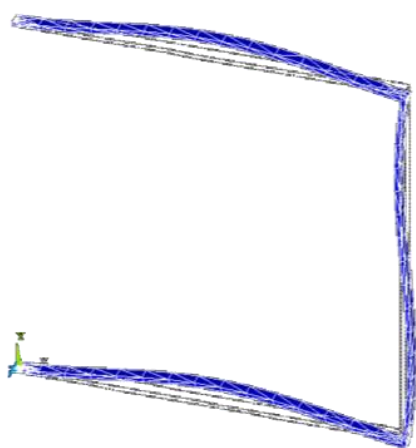

3. $\bmod$

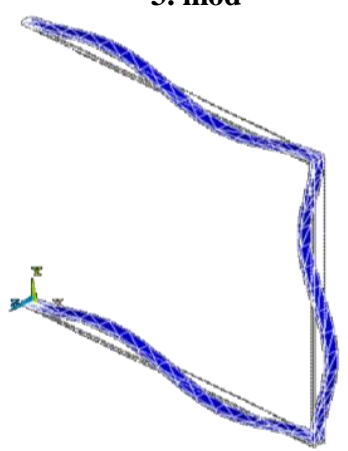

6. $\bmod$

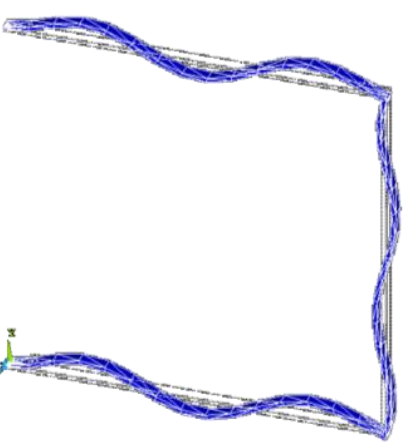

9. $\bmod$

Şekil 5. U çerçevenin sayısal modeline ait mod şekilleri

Tablo 1. U çerçevenin SE modeline ait doğal frekanslar

\begin{tabular}{cccccccccc} 
Tablo 1. U çerçevenin SE modeline ait doğal frekanslar \\
$\begin{array}{c}\text { Mod } \\
\text { Doğal Frekans }\end{array}$ & $\mathbf{1}$ & $\mathbf{2}$ & $\mathbf{3}$ & $\mathbf{4}$ & $\mathbf{5}$ & $\mathbf{6}$ & $\mathbf{7}$ & $\mathbf{8}$ & $\mathbf{9}$ \\
$(\mathbf{H z})$ & 8.81 & 37.36 & 58.40 & 62.46 & 145.46 & 166.58 & 188.49 & 235.09 & 292.71 \\
\hline
\end{tabular}




\section{Deneysel Model}

U çerçevenin deneysel modal analizi için yapılan ölçümlerde yapıyı titreştirmek için KISTLER firmasının üretmiş olduğu darbe çekici (Model: 9724A2000 S/N 2069942) ve yapının titreşimlerini ölçmek için Dytran firmasının üretmiş olduğu ICP tipi piezoelektrik ivmeölçer (3055 D serisi) kullanılmıştır. Ölçülen titreşim sinyallerinin toplanması ve analiz edilmesi için OROS firmasının Or36 serisi titreşim analizörü ve parametrelerin belirlenmesi için OROS Modal yazılımı kullanıld. Deneysel modal analiz için gerekli yazılım ve donanımlar belirlendikten sonra deney planlaması yapıldı. Deneysel planlamada amaç ölçülmek istenen frekans aralığına uygun tahrik ve cevap noktalarını belirlemektir. Yapının ölçülmek istenen frekans aralığındaki modlarda en çok hareket eden bölgeler en iyi ölçüm noktaları olarak değerlendirilmektedir. Modlardaki düğüm noktalarında (nodal point) hareket olmadığından bu noktalar en kötü ölçüm noktalarıdır. Benzer durum tahrik noktalarının belirlenmesi için de geçerlidir. Çalışma kapsamında hazırlanan deney düzeneğinin şematik gösterimi Şekil 6'da görülmektedir.

U çerçevenin deneysel modeli toplam 28 düğüm ve 27 elemandan oluşacak şekilde tasarlanmıştır (Şekil 7). Deneysel çalışmada kullanılan ölçüm parametreleri Tablo 2'de verilmiştir.

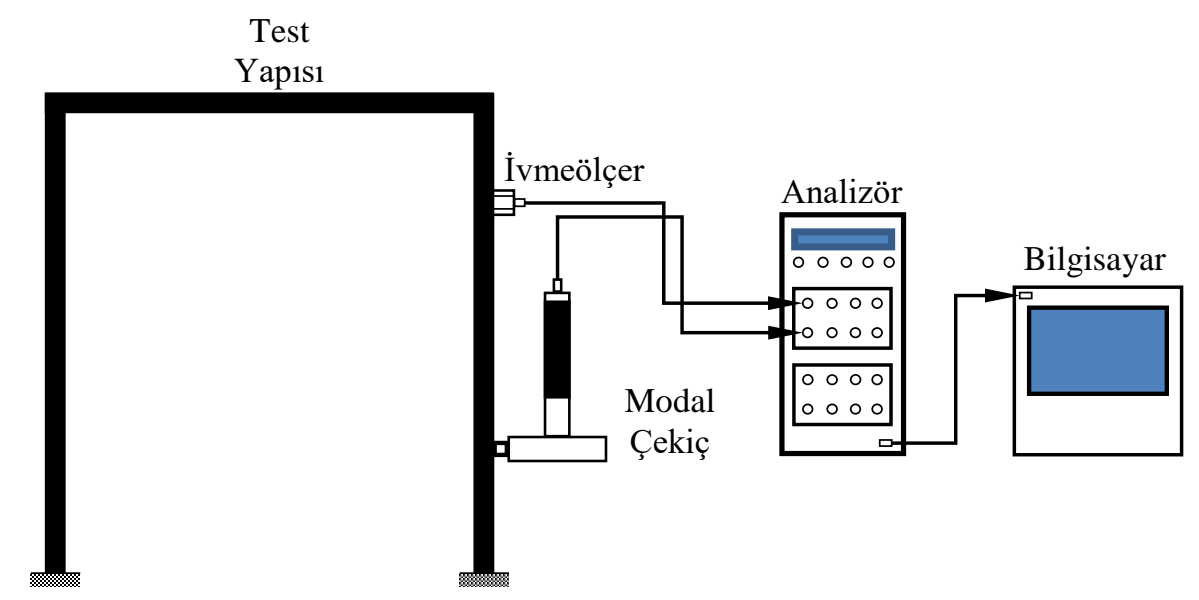

Şekil 6. Deney düzeneği

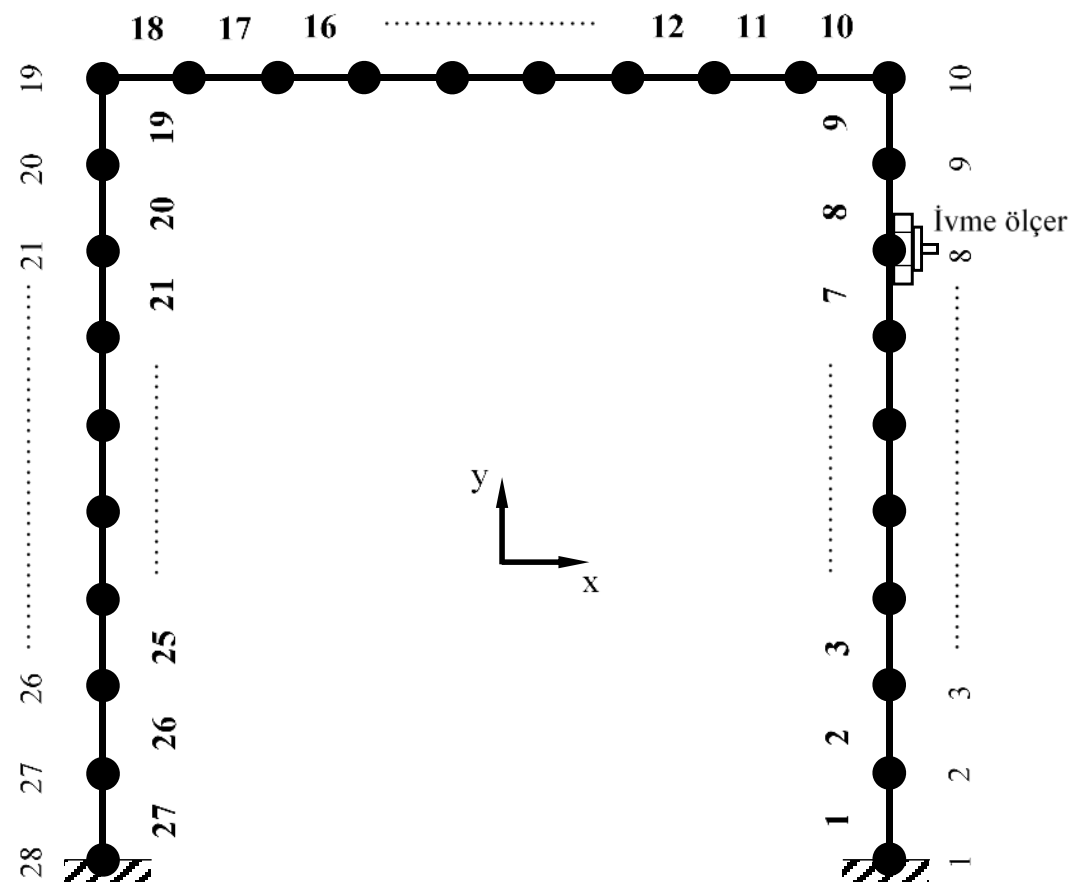

Şekil 7. U çerçevenin deneysel model

Tablo 2. Deneysel modal analiz için kullanılan ölçüm parametreleri

\begin{tabular}{llllll}
\hline Parametre & $\begin{array}{l}\text { Frekans } \\
\text { Genişliği (Hz) }\end{array}$ & $\begin{array}{l}\text { Frekans } \\
\text { Çözünürlüğ̈̈ (Hz) }\end{array}$ & $\begin{array}{l}\text { Örnekleme } \\
\text { Frekansı } \\
(\mathbf{H z})\end{array}$ & $\begin{array}{l}\text { Ölçüm Süresi } \\
(\mathbf{s n})\end{array}$ & $\begin{array}{l}\text { Pencereleme } \\
\text { (cevap/tahrik) }\end{array}$ \\
\hline Değeri & $0-500$ & 0.1 & 1001 & 2 & uniform/uniform \\
\hline
\end{tabular}


Deneylerde, U çerçeve yapının 8. düğümüne ivmeölçer yerleştirilip, her bir düğüme modal çekiçle darbe uygulanarak ilgili düğüm noktaları için FTF'ler elde edilmiştir. Deneysel modelin bazı koordinatlarına ait FTF'ler Şekil 8'de verilmiştir.

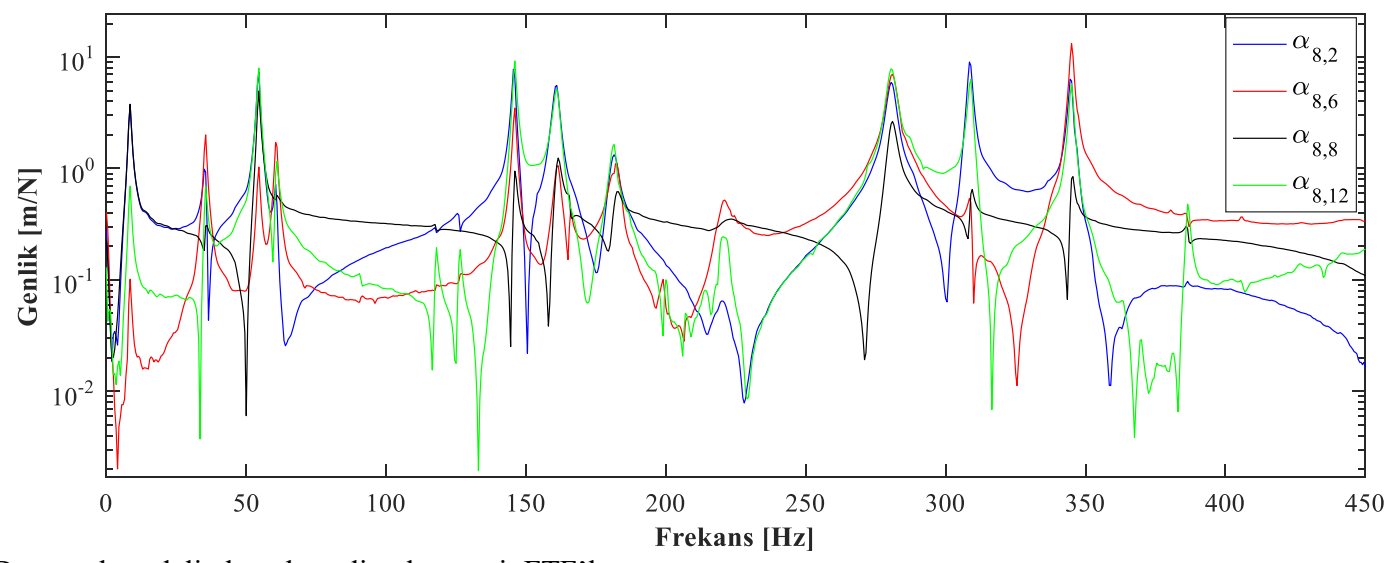

Şekil 8. Deneysel modelin bazı koordinatlarına ait FTF'ler

Şekil 8'de verilen FTF grafiklerindeki maksimum genliklere karşılık gelen noktalar rezonans frekanslarını (doğal frekanslar), minimum genlik değerlerine karşılık gelen noktalar ise anti rezonans frekanslarını göstermektedir. Bu şekilde 28 adet FTF ölçüldü ve ilk 9 mod için doğal frekanslar belirlendi. Deneysel ve sayısal modellerin doğal frekansları karşılaştırmalı olarak Tablo 3’te verilmiştir.

Tablo 3. Deneysel ve sayısal modellerin doğal frekanslarının karşılaştırılması

\begin{tabular}{|c|c|c|c|c|c|c|c|c|c|c|}
\hline \multicolumn{2}{|c|}{ Mod } & 1 & 2 & 3 & 4 & 5 & 6 & 7 & 8 & 9 \\
\hline \multirow{2}{*}{$\begin{array}{c}\text { Doğal } \\
\text { Frekans } \\
\text { (Hz) }\end{array}$} & Deneysel & 8.50 & 35.40 & 54.70 & 60.20 & 145.40 & 161.10 & 181.50 & 221.80 & 280.50 \\
\hline & Sayısal & 8.81 & 37.36 & 58.40 & 62.46 & 145.46 & 166.58 & 188.49 & 235.09 & 292.71 \\
\hline \multicolumn{2}{|c|}{ Mutlak Hata (\%) } & 3.65 & 5.54 & 6.76 & 3.75 & 0.04 & 3.40 & 3.85 & 5.99 & 4.35 \\
\hline
\end{tabular}

Tablo 3'te verilen doğal frekanslar incelendiğinde deneysel model ile sayısal modelin doğal frekansları arasındaki en küçük farkın $\% 0.04$ hata oranı ile 5 modunda oluştuğu görülmektedir. En büyük fark ise $\% 6.76$ ile 3 modunda meydana gelmiştir. Bunu sırası ile $\% 5.99, \% 5.54, \% 4.35, \% 3.85, \% 3.75, \% 3.65$ ve $\% 3.40$ hata oranlarının oluştuğu $8,2,9,7,4,1$ ve 6 modlarının doğal frekansları izlemiştir.

\section{SONUÇ}

Günümüzde düşük gürültülü ve yüksek güvenlikli makinelerin, konforlu taşıtların, dinamik yüklere karşı dayanıklı yapıların tasarlanması, emniyetli işletme şartlarının ve optimum çalışma parametrelerinin bulunması gibi çeşitli amaçlar için modal analiz metodu oldukça etkili bir şekilde kullanılmaktadır. Bu çalışmada iki ucu ankastre $U$ çerçevenin teorik ve deneysel modal analizleri yapılmış ve sonuçları karşılaştırmalı olarak sunulmuştur.

Yapılan analizlerde U çerçevenin ilk 9 modu dikkate alınmıştır. Yapının SE modeli ANSYS'te oluşturulmuş, deneysel model ise 28 dügüum 27 elemandan oluşacak şekilde tasarlanmıştır. Modal analizler sonucunda deneysel ve SE modellerin doğal frekansları arasındaki farkların \%0.04 ile \%6.76 arasında değişiklik gösterdiği belirlenmiştir. ANSYS'te oluşturulan modelin malzeme özellikleri, ağ yapısı ve mesnet bağlantıları gibi parametreler üzerinde değişiklikler yapılarak hata oranları azaltılabilir.

\section{KAYNAKÇA}

[1] Inman D.J. Engineering Vibration, Upper Saddle River New Jersey, 1997.

[2] Chen W.Q., Ding H.J. Natural frequencies of a fluidfilled anisotropic spherical Shell, The Journal of the Acoustical Society of America. 105 174-182, 1999.

[3] Dingand H.J., Chen W.Q. Nonaxisymmetric free vibrations of a spherically isotropic spherical shell embedded in an elastic medium, Int. J. Solids Struct. 33 2575-2590, 1996.

[4] Wu Y.C., Heyliger P. Free vibration of layered piezoelectric spherical caps, Journal of Sound and Vibration. 245 527-544, 2001.

[5] Lee J. Free vibration analysis of spherical caps by the pseudospectral method, Journal of Mechanical Science and Technology. 23 221-228, 2009.

[6] Krawczuk M., Ostachowicz W., Zak A. Modal analysis of cracked, unidirectional composite beam, Composites Part B: Engineering. 28 641-650, 1997.

[7] Maurinia C., Porfirib M., Pougeta J. Numerical methods for modal analysis of stepped piezoelectric beams, Journal of Sound and Vibration. 298 918-933, 2006. 
[8] Yoo H.H., Chob J.E., Chung J. Modal analysis and shape optimization of rotating cantilever beams, Journal of Sound and Vibration. 290 223-241, 2006.

[9] Gao W. Interval natural frequency and mode shape analysis for truss structures with interval parameters, Finite Elements in Analysis and Design. 42 471-477, 2006.

[10] Xu Y.L., Zhang W.S. Modal analysis and seismic response of steel frames with connection dampers, Engineering Structures. 23 385-396, 2001.

[11] Chan S.L. Vibration and modal analysis of steel frames with semi-rigid connections, Engineering Structures. 16 25-31, 2003.

[12] Evins D.J. Modal Testing: Theory, Practice and Application, Research Studies Press Limited, Hertfordshire, 1984.

[13] Balke H. Einführung in die Technische Mechanik, Springer Verlag, Berlin, 1956.

[14] Saad Y. Iterative Methods for Sparse Linear Systems, PWS Publishing Company, Boston, 1996.

[15] Grafe H. Model updating of large structural dynamics models using measured response functions, $\mathrm{PhD}$ Thesis, Imperial College of Science, Technology and Medicine University of London, 1998. 